\title{
Decomposing the effect of drug benefit program on antihypertensive medication adherence among the elderly in urban China
}

This article was published in the following Dove Press journal: Patient Preference and Adherence

\author{
Xiaochen $\mathrm{Ma}^{\mathrm{I}, *}$ \\ Yuji Zhang ${ }^{2, *}$ \\ Mei Zhang ${ }^{2}$ \\ Xiaoju $\mathrm{Li}^{2}$ \\ Hongpo Yin $^{2}$ \\ $\mathrm{Ke} \mathrm{Li}^{3}$ \\ Mingxia Jing ${ }^{2}$ \\ 'China Center for Health Development \\ Studies, Peking University, Beijing 100000, \\ People's Republic of China; ${ }^{2}$ Department \\ of Public Health, Shihezi University \\ School of Medicine, Shihezi 832002, \\ Xinjiang, People's Republic of China; \\ ${ }^{3}$ Department of Orthopedics, The First \\ Affiliated Hospital of the Medical College, \\ Shihezi University, Shihezi 832002, \\ Xinjiang, People's Republic of China \\ *These authors contributed equally to \\ this work
}

Correspondence: Mingxia Jing

Department of Public Health, Shihezi

University School of Medicine, $280 \mathrm{~N}$ 4th

Road, Shihezi, Xinjiang Uyghur

Autonomous Region 832002, People's

Republic of China

Tel + I 8299377776

Email jingmingxial63@I63.com
Purpose: Hypertension is a rapidly growing epidemic in People's Republic of China, yet it remains inadequately controlled. This study aimed to identify the relative contributions of program effects and patients' characteristics to the differences in antihypertensive medication nonadherence between drug benefit program enrollees and non-enrollees.

Patients and methods: Data were from a cross-sectional survey of 1,969 communitydwelling elderly adults with hypertension. Self-reported adherence was measured following previous studies in People's Republic of China. The Blinder-Oaxaca nonlinear decomposition method was used to identify the relative contributions of program effects and patients' individual characteristics.

Results: Eleven percent of the drug benefit program enrollees were nonadherent to their medication, while $17 \%$ of non-enrollees were. Blinder-Oaxaca decomposition identified that over $60 \%$ of the gap between the two groups was due to the program effects $(P=0.024)$. The rest could be explained by differences in observable characteristics $(P<0.001)$, such as diabetic status, duration of hypertension, and blood pressure control.

Conclusion: The study confirmed that drug benefit program enrollees were more likely to be adherent to their antihypertensive medication than non-enrollees in the context of People's Republic of China.

Keywords: medication adherence, drug benefit program, decomposition, hypertension

\section{Introduction}

Hypertension is a major health problem and significantly contributes to morbidity and mortality worldwide. ${ }^{1}$ Approximately $45 \%$ of Chinese adults aged 35-75 years have hypertension, only about $7.2 \%$ of whom have their blood pressure controlled. ${ }^{2}$ Nonadherence to antihypertensive medication regimen has long been recognized as a substantial roadblock to achieving better outcomes for patients with hypertension. ${ }^{3}$ The cost of medications, among other reasons, was one of the well-documented reasons that patients missed their doses either intentionally or unintentionally. ${ }^{4}$ To address this cost-related poor adherence issue, People's Republic of China has piloted drug benefit programs to reduce the out-of-pocket costs of prescription drugs for eligible patients with chronic diseases at provincial level in recent years. ${ }^{5-7}$ For example, starting 2015 in Xinjiang Uygur Autonomous Region, eligible hypertensive enrollees of Urban Employees Basic Medical Insurance (UEBMI) were provided with drug benefit program coverage for antihypertensive drugs. ${ }^{8-10}$ 
Previous studies in other settings (mostly in the US) have found that drug benefit program coverage was associated with higher medication adherence, ${ }^{11-14}$ however, published research on the drug benefit program among patients with hypertension in the context of People's Republic of China, is scarce. To date, most of the drug benefit programs in People's Republic of China are in the early pilot stage of evaluation and adjustment. In order to improve the efficacy and targeting of those programs, rigorous quantitative evidence using data from People's Republic of China is needed. Specifically, two questions need to be answered: first, how do you isolate the program's effect from differences in patients' characteristics? Drug benefit programs select different types of patients, so to what extent can the observed differences between program enrollees and non-enrollees be attributed to the effect of the program on the one hand and to the fact that patients in the two groups are systematically different to begin with on the other hand $?^{15-18}$ Second, how can the heterogeneity of program effects be understood? In other words, how can those patients who are more likely to respond to the program and achieve higher medication adherence be identified?

To fill this gap, we used decomposition methodology to quantify the proportion of each risk factor which contributes to the differences in observed medication nonadherence according to drug benefit program enrollment status. Specifically, we had two objectives: first, to identify the relative contributions of program effects and patients' individual characteristics. Second, to determine the those patients who would benefit better than others when covered by the same drug benefit program.

\section{Materials and methods}

\section{Setting and study design}

Since January 2015, UEBMI piloted a drug benefit program which provided eligible enrollees (with hypertension) with a $60 \%-80 \%$ reimbursement of medication cost with a deductible of 100 RMB (or US\$15) and a limit of 1,500-2,000 RMB (or US\$225-300) per year. A crosssectional survey on medication adherence was performed from April to August 2016. The questionnaire included demographic characteristics, health conditions, access to care, drug benefit program coverage, and household income. In addition, medication adherence and blood pressure were measured. The study was approved by the Ethics Committee of the Shihezi University. During the survey period, investigators read and explained the informed consent, and all patients gave written informed consent (signed or fingerprinted if illiterate) before the questionnaire began. The data collected in the survey were then merged with insurance claims data to identify the drug benefit program enrollment status.

\section{Study subjects}

Participants were enrolled using the following criteria: individuals who: 1) were diagnosed with hypertension by clinical doctors with systolic blood pressure $\geq 140 \mathrm{mmHg}$ and/or diastolic blood pressure $\geq 90 \mathrm{mmHg}$; 2) were managed by local community during the survey period; and 3 ) were taking at least one antihypertensive medication during the survey period.

The exclusion criteria were as follows: patients who: 1) had communication difficulties such as visual impairment and poor hearing; 2) exhibited severe cognitive impairment or had been diagnosed with dementia and mental disorder; 3) were too sick to participate in this study; and 4) were uncooperative.

For each respondent, blood pressure was measured with a sphygmomanometer three times at 45 -second intervals 5-10 minutes after the completion of the questionnaire. Our final sample included 1,969 elderly adults with hypertension of whom $29.8 \%(n=586)$ were enrolled in drug benefit program.

\section{Outcome measures and covariates}

The outcome variable for this study was antihypertensive medication adherence, measured by a four-item interview instrument. This four-item interview instrument was based on previous studies conducted in a Chinese setting. ${ }^{19,20}$ Specifically, patients were asked: 1) can you take your antihypertensive medication every day based on the required frequency of your prescription? 2) Can you take your antihypertensive medication every day based on the required timing of your prescription? 3) Can you take your antihypertensive medication every day based on the required dose of your prescription? 4) Do you continuously take your antihypertensive medication? The first three questions were coded with 4-scale answers: 1) never complete, 2) sometimes complete, 3) usually complete, and 4) always complete. The last question was coded with different 4-scale answers: 1) discontinued the medication, 2) took the medications intermittently, 3) took the medications continuously but below the prescribed dose, and 4) took the medications continuously without 
interruption. The participants who chose either the third or the fourth options as answers to all four questions were identified as adherent; those who did not were considered as nonadherent. A binary variable of medication nonadherence was used in data analysis.

Following Andersen's behavioral model of health service use, the present study included covariates from the three dimensions: predisposing, enabling, and need-related factors. ${ }^{21,22}$ Predisposing factors described the propensity of individuals to use services, including gender, age, and education level. Enabling factors described the means and access that individuals have available to them for the use of services. Variables of annual household income, urban residence, and frequency of clinic check-ups were included. Frequency of clinic check-ups was measured as a polytomous variable indicating how many times the individuals visited a clinic to monitor their health conditions over the past 12 months. Need factors reflected the most immediate cause for health services use, including diabetic status, duration of hypertension, and control of blood pressure. Diabetic status reflected the comorbid condition if a respondent had diabetes mellitus. Blood pressure control was defined as systolic blood pressure $<140 \mathrm{mmHg}$ and diastolic blood pressure $<90 \mathrm{mmHg}$.

\section{Statistical analysis}

Group differences between enrollees and non-enrollees were examined by chi-squared test and the MannWhitney U test. Multiple logistic regression analysis was performed with medication nonadherence as the dependent variable for samples of enrollees and non-enrollees separately.

Due to the binary nature of our outcome variable, an extension of Blinder-Oaxaca decomposition method for nonlinear model was used to explain the disparities in medication nonadherence between enrollees and nonenrollees. The Blinder-Oaxaca decomposition method was originally developed to explain wage gaps between whites and blacks and between men and women since the seminal work of Oaxaca and Blinder in the early 1970s. ${ }^{23,24}$ The following equation described how the Blinder-Oaxaca decomposition method disentangled and quantified the nonadherence gap between enrollees and non-enrollees into two parts:

$$
\mathrm{E}\left(\mathrm{P}_{\mathrm{n}}-\mathrm{P}_{\mathrm{e}}\right)=\left(\mathrm{E}\left[\mathrm{Z}_{\mathrm{n}}\right]-\mathrm{E}\left[\mathrm{Z}_{\mathrm{e}}\right]\right) \beta_{\mathrm{e}}+\mathrm{E}\left[\mathrm{Z}_{\mathrm{n}}\right]\left(\beta_{\mathrm{n}}-\beta_{\mathrm{e}}\right)
$$

Where $\mathrm{n}$ represented non-enrollees and e represented enrollees; $\mathrm{Z}$ represented all the observed characteristics that appeared in our study; $\beta$ represented the estimated coefficients. The first term in Equation (1) corresponded to the proportion of the gap in outcomes between two groups that were accounted for by group differences in the distribution of observable characteristics (the explained component in decomposition literature) - in our case, the part caused by differences in patients' characteristics. The second term corresponded to the proportion of the gap in outcomes between two groups that were accounted for by differences in the effects of these characteristics (the unexplained component in decomposition literature) - in our case, the part caused by differences in program effects.

The "overall" explained and unexplained components could be further broken down into individual terms because of particular covariates which we described in the previous section as "detailed" explained and unexplained decomposition components. All analyses were conducted using Stata 14.0 (Yun et al's work contains details of running the nonlinear Blinder-Oaxaca decomposition package). ${ }^{25}$

\section{Results}

\section{Characteristics of study population}

Table 1 provides descriptive statistics for all subjects as well as a comparison of all covariates between enrollment status. An amount of $10.6 \%$ of the program enrollees were not adherent to their antihypertensive medication, whereas $16.6 \%$ of non-enrollees were $(P=0.001)$. Statistically significant differences were found in the level of all covariates, except for urbanity $(P=0.853)$ and blood pressure control $(P=0.106)$. Compared to non-enrollees, drug benefit program enrollees comprised less females $(54.3 \%$ vs $62.4 \%)$, were older ( 72.8 vs 72.0$)$, less illiterate $(32.3 \%$ vs $41.1 \%$ ), and more likely to live in higher income families ( $43.5 \%$ vs $29.9 \%)$. They were also more likely to have clinic check-ups $(86.0 \%$ vs $77.5 \%)$, comorbidity of diabetes (35.3\% vs $29.5 \%)$, and duration of hypertension over 10 years $(73.5 \%$ vs $55.8 \%)$.

\section{Determinants of nonadherence by enrollment status}

Figure 1 plots the OR of the multiple logistic regression of medication nonadherence on to predisposing factors, enabling factors, and need covariates for enrollees and non-enrollees separately (details are shown in Table S1). None of the three predisposing factors including gender, age, and education was significantly associated with 
Table I Characteristics of study population ${ }^{\mathrm{a}}$

\begin{tabular}{|c|c|c|c|c|}
\hline Variables & $\begin{array}{l}\text { Total } \\
(n=I, 969)\end{array}$ & $\begin{array}{l}\text { Enrollees } \\
(n=586)\end{array}$ & $\begin{array}{l}\text { Non-enrollees } \\
(n=I, 383)\end{array}$ & $P$ \\
\hline Medication adherence & & & & 0.001 \\
\hline No & 291 (I4.8\%) & $62(10.6 \%)$ & $229(16.6 \%)$ & \\
\hline \multicolumn{5}{|l|}{ Predisposing factors } \\
\hline Gender & & & & 0.001 \\
\hline Female & II8I (60.0\%) & $318(54.3 \%)$ & $863(62.4 \%)$ & \\
\hline $\mathrm{Age}^{\mathrm{b}}$ & $72.26(7.69)$ & $72.80(7.05)$ & $72.04(7.94)$ & 0.021 \\
\hline Education & & & & 0.001 \\
\hline Illiterate & 757 (38.4\%) & $189(32.3 \%)$ & $568(41.1 \%)$ & \\
\hline Primary school & $644(32.7 \%)$ & $206(35.2 \%)$ & $438(31.7 \%)$ & \\
\hline Middle school or above & $568(28.8 \%)$ & 191 (32.6\%) & 377 (27.3\%) & \\
\hline \multicolumn{5}{|l|}{ Enabling factors } \\
\hline Annual household income (yuan) & & & & $<0.001$ \\
\hline$<48,000$ & $618(31.4 \%)$ & |3| (22.4\%) & 487 (35.2\%) & \\
\hline $48,000-68,400$ & $682(34.6 \%)$ & $200(34.1 \%)$ & 482 (34.9\%) & \\
\hline$\geq 68,400$ & $669(34.0 \%)$ & 255 (43.5\%) & $414(29.9 \%)$ & \\
\hline Urbanity & & & & 0.853 \\
\hline Urban & $599(30.4 \%)$ & $180(30.7 \%)$ & $419(30.3 \%)$ & \\
\hline Frequency of clinic check-ups (times over the past 12 months) & & & & $<0.001$ \\
\hline 0 & $393(20.0 \%)$ & $82(14.0 \%)$ & $311(22.5 \%)$ & \\
\hline $\mathrm{I}-2$ & $557(28.3 \%)$ & I 58 (27.0\%) & $399(28.9 \%)$ & \\
\hline$\geq 3$ & $1019(51.8 \%)$ & $346(59.0 \%)$ & $673(48.7 \%)$ & \\
\hline \multicolumn{5}{|l|}{ Need } \\
\hline Diabetic status & & & & 0.011 \\
\hline Yes & $615(31.2 \%)$ & $207(35.3 \%)$ & 408 (29.5\%) & \\
\hline Duration of hypertension (years) & & & & $<0.001$ \\
\hline $1-5$ & 305 (15.5\%) & $44(7.5 \%)$ & $26 I(18.9 \%)$ & \\
\hline $5-10$ & $46 \mid(23.4 \%)$ & III (I8.9\%) & $350(25.3 \%)$ & \\
\hline$\geq 10$ & $1203(61.1 \%)$ & 431 (73.5\%) & $772(55.8 \%)$ & \\
\hline Blood pressure control & & & & 0.106 \\
\hline Controlled & 786 (39.9\%) & 250 (42.7\%) & $536(38.8 \%)$ & \\
\hline
\end{tabular}

Notes: ${ }^{a}$ Unless indicated, numbers presented are n, \%. ${ }^{b}$ Numbers presented are mean, SD.

medication nonadherence in both groups. More than three times, clinic check-up visits was the only enabling variable that was significantly associated with medication nonadherence, and with a negative sign in both groups. For the need factors, controlling blood pressure had a significant negative relationship with medication 


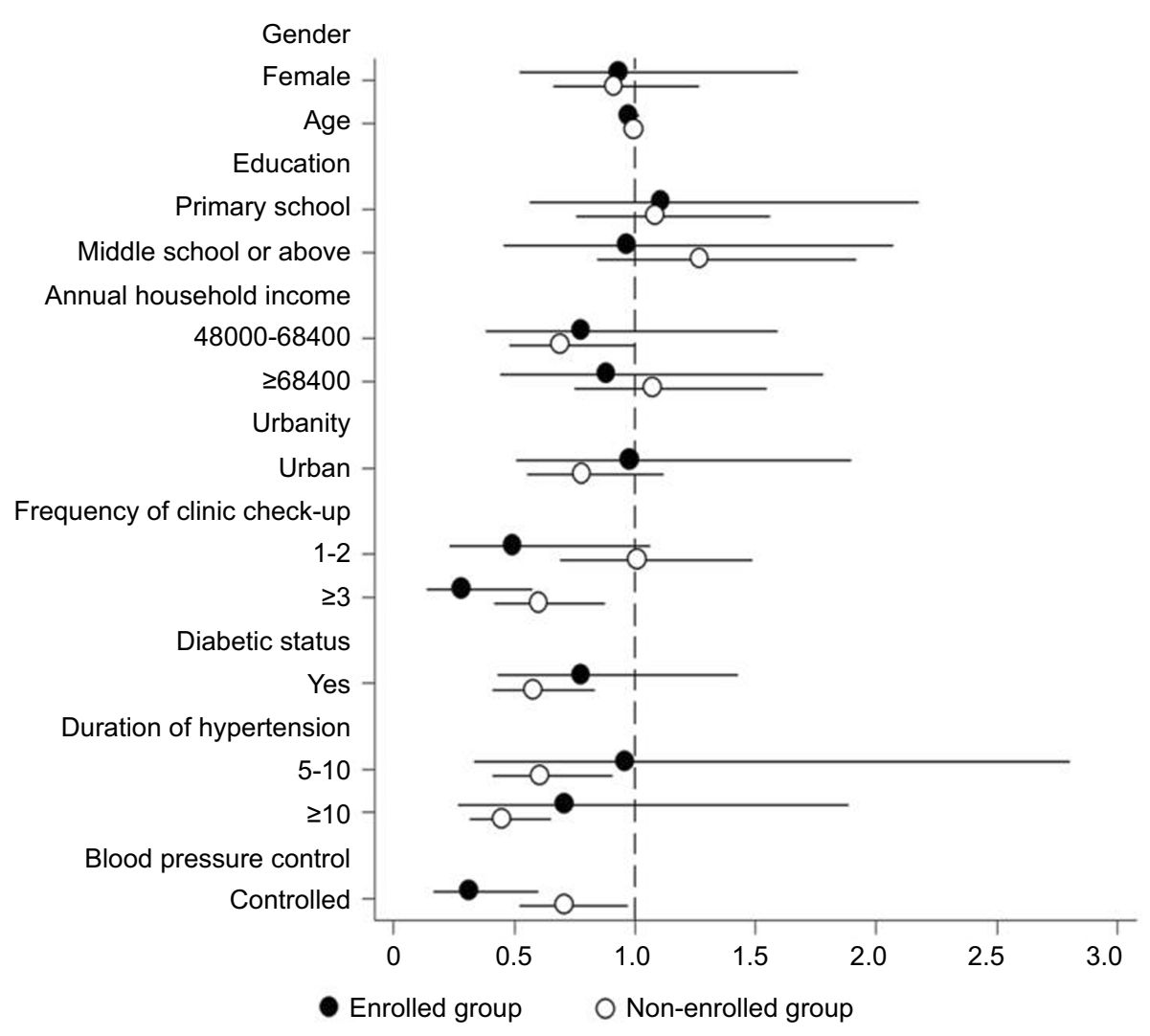

Figure I OR for medication nonadherence by drug benefit program enrollment status. Notes: The x-axis refers to magnitude of the OR. Black horizontal lines reflect $95 \% \mathrm{Cls}$.

nonadherence in both groups. Having diabetes and longer duration of hypertension were only significantly and negatively associated with medication nonadherence in the non-enrolled group.

\section{Decomposing nonadherence gap between enrolled and non-enrolled groups}

Table 2 presents the decomposition results for difference in medication nonadherence between enrollees and nonenrollees, using enrollees as the reference group. The probability of medication nonadherence for non-enrollees was 0.17 , and 0.11 for program enrollees. The 6 percentage points gap between the two groups was largely due to the program effects (the unexplained component: 3.7 percentage points or $60.9 \%$ in relative terms; $P=0.024$ ). Detailed decomposition analysis of the unexplained component (details are shown in Table S2) showed that the patients who had more clinic check-ups over the past 12 months $(P=0.038)$, or those with controlled blood pressure $(P=0.005)$ had lower medication nonadherence in the enrollees group compared with similar patients in the non-enrollees group (Figure 2). In other words, program effects were positively associated with clinic check-ups and blood pressure control. We also found that program effects were negatively associated with having diabetes and longer duration of hypertension, although not statistically significant.

Differences in the levels of observable patient characteristics (or the explained component) accounted for 2.3 percentage points or $39.1 \%$ in relative terms $(P<0.001)$ of the overall gap. Detailed decomposition analysis of the explained component (details are shown in Table S3) found that the differences in the level of need factors explained the greatest portion of the gap, accounting for $35.1 \%$. Duration of hypertension was the most powerful explanatory variable in the model, increasing the gap by almost $32.1 \%(P<0.001)$, diabetic status increased the gap by $7.2 \%(P=0.001)$ (Figure 3$)$.

\section{Discussion}

WHO listed nonadherence to medication as a "worldwide problem of striking magnitude". ${ }^{26}$ This problem is particularly relevant for the treatment of chronic diseases such as hypertension: on the one hand, missing doses more 
Table 2 Blinder-Oaxaca nonlinear decomposition of the differences in medication nonadherence between drug benefit program enrollees and non-enrollees

\begin{tabular}{|c|c|c|c|c|c|}
\hline & $\begin{array}{l}\text { Non- } \\
\text { enrollees }\end{array}$ & Enrollees & $\begin{array}{l}\text { Difference } \\
\text { (non-enrol- } \\
\text { lees - } \\
\text { enrollees) }\end{array}$ & $\begin{array}{l}\text { Difference attributed to dif- } \\
\text { ferences in program effect } \\
\text { (unexplained component) }\end{array}$ & $\begin{array}{l}\text { Difference attributed to dif- } \\
\text { ferences in observed char- } \\
\text { acteristics (explained } \\
\text { component) }\end{array}$ \\
\hline Probability of nonadherence & 0.17 & 0.11 & 0.06 & 0.037 & 0.023 \\
\hline$P$-value & - & - & $<0.001$ & 0.024 & $<0.001$ \\
\hline$\%$ of contribution & - & - & - & $60.90 \%$ & $39.10 \%$ \\
\hline
\end{tabular}

likely results in salient health and economic consequences in the longer term instead of short term; on the other hand, compliance to medications means costs to the patients and families on a daily basis. ${ }^{4,27}$ In our study, drug benefit program coverage that reduced the out-of-pocket expenses of hypertensive patients was associated with better mediation compliance: non-enrollees were more than one and a half times likely to report medication nonadherence than enrollees of such program. The non-enrollees were more likely to be female, illiterate, living in lower income families, have shorter duration of hypertension, and less likely to have clinic check-ups, with comorbidity of diabetes, compared to their counterparts in the enrolled group. This systematic difference in distribution of characteristics revealed in descriptive analysis was consistent with the findings in other settings that drug benefit programs selected in different types of patients. ${ }^{28,29}$ It would be reasonable to expect that some of these group differences might explain the drug benefit program non-enrollees' higher rates of medication nonadherence. Therefore, rigorous quantitative investigation of the role of drug benefit program needed to take into account the relative contribution of the group differences in patients' characteristics in order to isolate the program effects.

The decomposition analysis suggested that not only were drug benefit program enrollees different from nonenrollees - in other words, program selected in patients with different characteristics - but the program coverage itself might have an impact on medication adherence outcomes. Only about $40 \%$ of the gap in medication nonadherence between enrollees and non-enrollees can be explained by difference in the levels of observable characteristics (or the explained component). We found that need factors contributed to the major difference in medication nonadherence rather than predisposing factors and enabling factors. The findings of the contribution of the duration of hypertension and comorbidity of diabetes on medication nonadherence differences in the present study paralleled that of previous studies of medication nonadherence in the US Medicare population. ${ }^{16,17}$ The majority of the gap $(60 \%)$ in medication nonadherence between enrollees and non-enrollees, however, was attributed to the program effect (or the unexplained component). Previous studies suggested the remaining unexplained component might be caused by the fact that program coverage changes medication taking behaviors as well as the behaviors of physicians. For example, lower outof-pocket medication spending might make patients more likely to take drugs, ${ }^{15,30-32}$ and physicians might prescribe different types of antihypertension medications to program enrollees..$^{18,33,34}$ However, our decomposition analysis could not help to explain whether it was those other factors that caused the medication nonadherence gap.

Previous studies about the role of drug benefit programs on medication adherence mostly used claims data in the US setting and applied standard regression analysis. ${ }^{4,30,35}$ Hence, it was difficult to compare our findings. Nevertheless, our decomposition analysis improved the existing work from methodological and policy perspectives: first, BlinderOaxaca decomposition is an established methodology for investigating differences between groups, originally in the field of social-economic inequalities. ${ }^{36}$ In the field of public health, decomposition analysis has been applied to study the disparities in health outcomes and health service utilizations according to race and other important social-economic variables. ${ }^{37-39}$ Very few studies have applied the decomposition method to investigate the effect of a program or treatment. One recent work using clinical data to decompose the source of differences in outcome between two type-2 diabetes therapies was a welcome exception. ${ }^{40}$ To our knowledge, our study was the first to apply decomposition analysis to investigate the effect of a drug benefit program on medication adherence among elderly patients with hypertension in People's Republic of China. Second, the decomposition analysis allowed us to quantify the proportion that each 


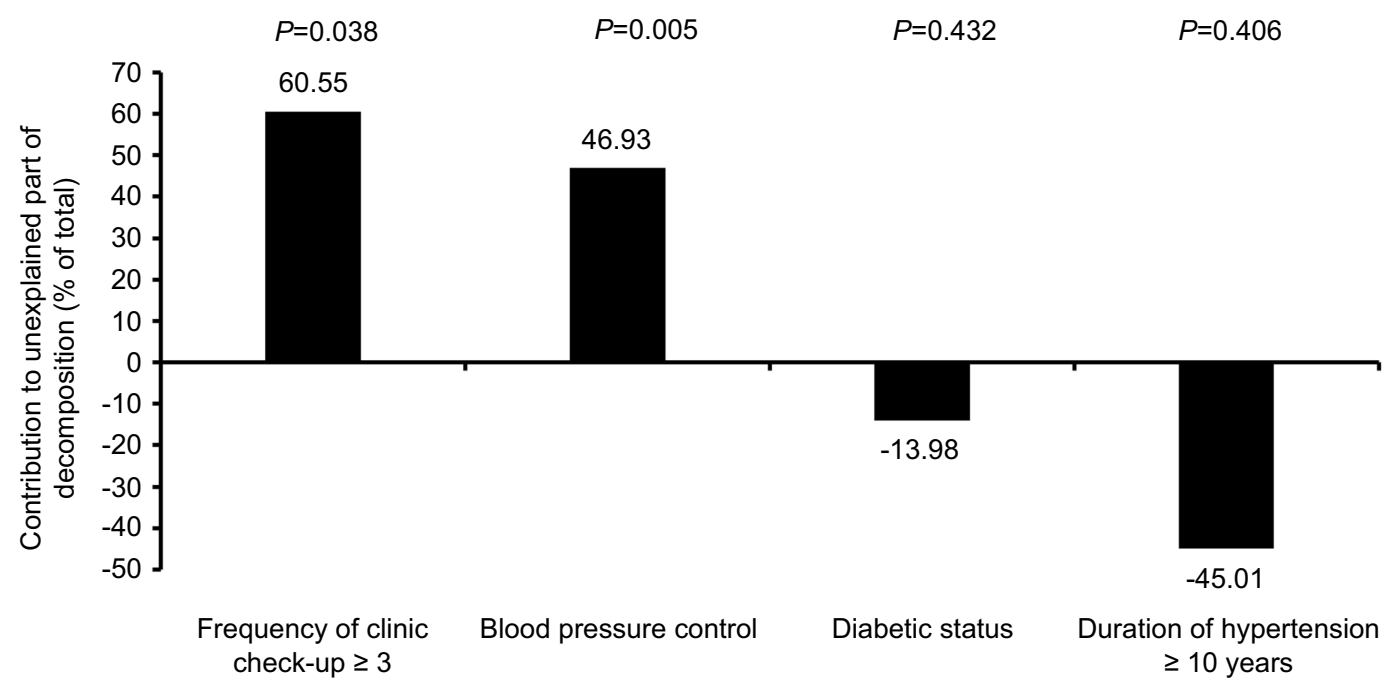

Positive value $=$ great increase in medication nonadherence when non-enrollees compared with enrollees Negative value $=$ great increase in medication nonadherence when enrollees compared with non-enrollees.

Figure 2 Contribution of drug benefit program effects to antihypertensive medication nonadherence.

Notes: Other observed characteristics adjusted for in the decomposition analysis were gender, age, education, annual household income, urbanity, other frequency of clinic check-ups, and other duration of hypertension.

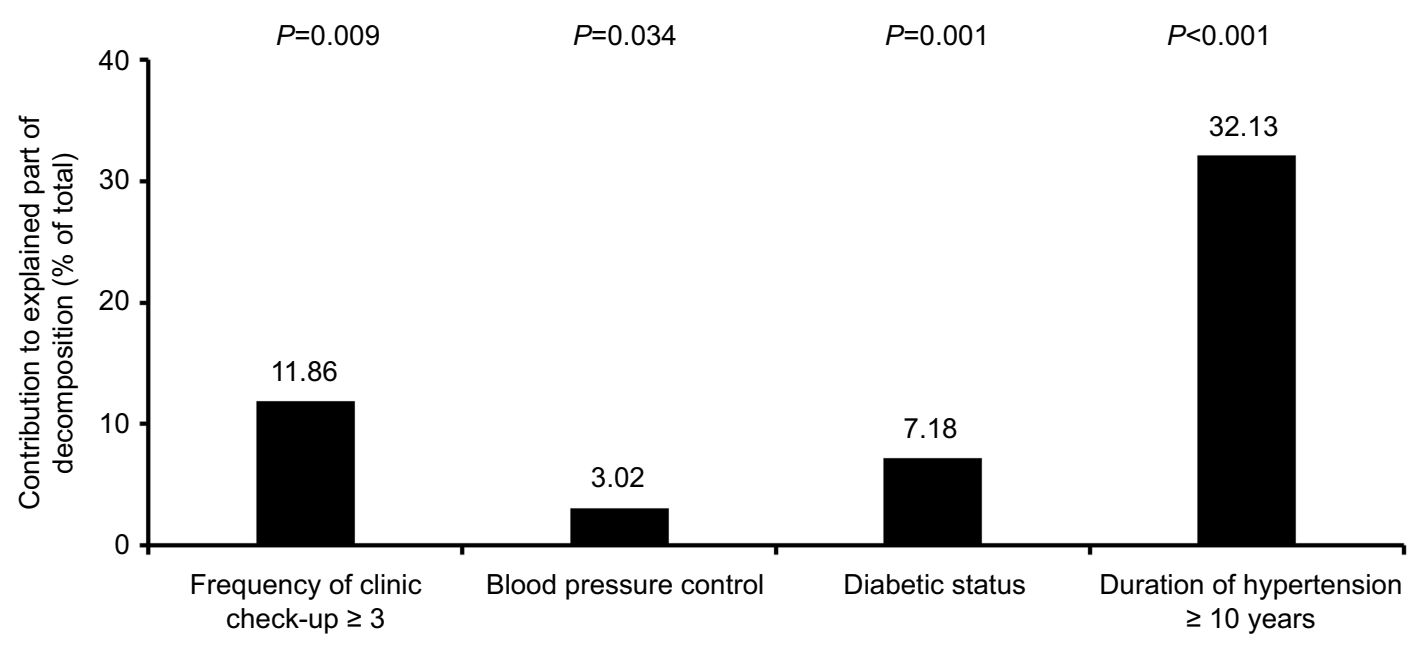

Positive value $=$ great increase in medication nonadherence when non-enrollees compared with enrollees. Negative value $=$ great increase in medication nonadherence when enrollees compared with non-enrollees

Figure 3 Contribution of observable characteristics to antihypertensive medication nonadherence.

Notes: Other observed characteristics adjusted for in the decomposition analysis were gender, age, education, annual household income, urbanity, other frequency of clinic check-ups, and other duration of hypertension.

covariate contributed to the differences in medication nonadherence by drug benefit program coverage. In particular, we were able to not only isolate the proportion of patient characteristics and program effect which contributed to the medication nonadherence gaps, but also the specific covariables that might be associated with higher program benefits if coverage was provided. Hence, our results were useful to shed some light on improving the efficacies and targeting of drug benefit programs.
Our study has several limitations. First, the observational nature of our study limited the interpretation of our findings to causal inference. We did not attempt to account for selection into the drug benefit program, which was by all means not random. There are a number of reasons why patients might choose to enroll in the program if eligible, and those same reasons might also influence their decisions to use medications. In previous studies of non-random assignment of program enrollment, instrumental 
variables (IV) method was used to account for endogeneity issue. $^{41}$ Future studies should consider applying IV to provide a better insight into causal inference of the program effect. Second, similar to standard regression analysis, the decomposition method had to concern about omitted variables. Although we have controlled a series of predisposing, enabling, and need factors that should predict medication adherence, it was possible that some potentially important confounding factors - for example, physician behaviors - were not included due to data limitations. In fact, our decomposition results showed the unexplained component absorbed more than half of the total disparity in medication nonadherence. In the decomposition analysis, we followed the decomposition literature and interpreted the contribution of those additional unobserved variables to the total gap as the program effect (or unexplained component). However, if those variables were measured and included in the model, less of the total gap would be left as unexplained and therefore we might have a smaller program effect. Finally, our sample population in Xinjiang Uygur Autonomous Region might differ from other parts of People's Republic of China, which might limit the generalization of our results. Although, the sample in our study was from northern Han majority area, where the demographic characteristics are similar to the average People's Republic of China. ${ }^{42,43}$

\section{Conclusion}

In summary, our study confirmed that drug benefit program enrollees were more likely to be adherent to their antihypertensive medication than non-enrollees. The decomposition analysis results showed that the drug benefit program accounted for most of the disparity in medication nonadherence. In view of the growing epidemic of hypertension and rapid pace of population aging in People's Republic of China, we believ our findings shed light on designing polices for hypertensive patients and therefore achieving optimal hypertension management. Future research should include important factors such as medication taking or physician behavioral differences.

\section{Acknowledgments}

We sincerely acknowledge those patients who participated in the survey. We are grateful to Lu Mao, Yinxia Zheng, Wangfei Cui, Yanli He, Yan Huang, and all college students who participated in our survey for data collection. We would like to thank Rujiang Liang for STATA programming. We would also like to thank the Department of
Public Health, Shihezi University School of Medicine, for providing assistance.

\section{Disclosure}

The authors report no conflicts of interest in this work.

\section{References}

1. Olsen MH, Angell SY, Asma S, et al. A call to action and a lifecourse strategy to address the global burden of raised blood pressure on current and future generations: the Lancet commission on hypertension. Lancet. 2016;388:2665-2712. doi:10.1016/S0140-6736(16) 31134-5

2. Lu J, Lu Y, Wang X, et al. Prevalence, awareness, treatment, and control of hypertension in China: data from 1.7 million adults in a population-based screening study (China PEACE Million Persons Project). Lancet. 2017;390(10112):2549-2558. doi:10.1016/S01406736(17)32478-9

3. Osterberg L, Blaschke T. Adherence to medication. $N$ Engl J Med. 2005;353(18):487-497. doi:10.1056/NEJMra050100

4. Mojtabai R, Olfson M. Medication costs, adherence, and health outcomes among Medicare beneficiaries. Health Aff (Millwood). 2003;22(4):220-229. doi:10.1377/hlthaff.22.4.220

5. Wang Y. Investigation and Prevention on Chronic Disease in China. Beijing: China Social Sciences Press; 2011:39-40.

6. Zhong H. Effect of patient reimbursement method on health-care utilization: evidence from China. Health Econ. 2011;1312-1329. doi: $10.1002 /$ hec. 1670

7. Zhang WJ. The Research of the Urban Employee Medical Insurance for Outpatient Health Service. Nanjing, Jiangsu, China: Southest University Press; 2016:6-12.

8. Xinjiang Production and Construction Corps thirteenth division of government affairs network. Medical insurance policy guide. Available from: http://www.btnsss.gov.cn/gk/yewugongzuo/bdw/ 22109.htm. Accessed March 2, 2018.

9. The Six Division of Wujiaqu City. Document on the uniform policy of the implementation corps of medical insurance policy of divison and city. Available from: http://www.wjq.gov.cn/xxbssg/100678.htm. Accessed March 2, 2018.

10. Shihezi City of Xinjiang. Document on the identification and application of drug benefit program in the urban employees basic medical insurance in 2015. Available from: http://www.shz.gov.cn/structure/ newSite/New_Channel_1/New_Page_2?infid=2558. Accessed March 2, 2018.

11. Chernew ME, Shah MR, Wegh A, et al. Impact of decreasing copayments on medication adherence within a disease management environment. Health Aff. 2008;27(1):103-112. doi:10.1377/ hlthaff.27.1.103

12. Yu B, Zhang X, Wang G. Full coverage for hypertension drugs in rural communities in China. Am J Manag Care. 2013;19(1):e22-e9.

13. Maimaris W, Paty J, Perel P, et al. The influence of health systems on hypertension awareness, treatment, and control: a systematic literature review. PLoS Med. 2013;10(7):e1001490. doi:10.1371/journal. pmed. 1001490

14. Zhang YJ, Li XJ, Mao L, et al. Factors affecting medication adherence in community-managed patients with hypertension based on the principal component analysis: evisence from Xinjiang, China. Patient Prefer Adherence. 2018;5(12):803-812. doi:10.2147/PPA.S158662

15. Doll JA, Hellkamp AS, Goyal A, Sutton NR, Peterson ED, Wang TY. Treatment, outcomes, and adherence to medication regimens among dual Medicare-Medicaid-eligible adults with myocardial infarction. JAMA Cardiol. 2016;1(7):787-794. doi:10.1001/ jamacardio.2016.2724 
16. Mazzaglia G, Ambrosioni E, Alacqua M, et al. Adherence to antihypertensive medications and cardiovascular morbidity among newly diagnosed hypertensive patients. Circulation. 2009;120(16):15981605. doi:10.1161/CIRCULATIONAHA.108.830299

17. Bandi P, Goldmann E, Parikh NS, Farsi P, Bodenalbala B. Age-related differences in antihypertensive medication adherence in Hispanics: a cross-sectional community-based survey in New York city, 2011-2012. Prev Chronic Dis. 2017;14:E57. doi:10.5888/pcd14.160512

18. Cho MH, Yoo KB, Lee HY, et al. The effect of new drug pricing systems and new reimbursement guidelines on pharmaceutical expenditures and prescribing behavior among hypertensive patients in Korea. Health Policy. 2015;119(5):604-611. doi:10.1016/j.healthpol.2015.01.002

19. Ye XQ, Lin FY, Chen WQ. Study on influence factoes of compliance to antihypertensive medications. Mod Preventive Med. 2007;34(3):494 496

20. Ye XQ, Liu YL, Chen WQ. Knowledge, health beliefs in hypertensive patients and its influence on durg compliance. Chin J Nurs. 1998;33(11):624-626.

21. Aday LA, Andersen R. A framework for the study of access to medical care. Health Serv Res. 1974;9(3):208-220.

22. Mekonnen HS, Gebrie MH, Eyasu KH, et al. Drug adherence for antihypertensive medications and its determinants among adult hypertensive patients attending in chronic clinics of referral hospitals in Northwest Ethiopia. BMC Pharmacol Toxicol. 2017;18(1):27. doi:10.1186/s40360-017-0134-9

23. Blinder AS. Wage discrimination: reduced form and structural estimates. J Hum Resour. 1973;8(4):436-455. doi:10.2307/144855

24. Oaxaca R. Male-Female wage differentials in urban labor markets. Int Econ Rev (Philadelphia). 1973;14(3):693-709. doi:10.2307/2525981

25. Yun MS, Powers DA, Yoshioka H. Mvdcmp: multivariate decomposition for nonlinear response models. Stata J. 2012;11(4):556-576.

26. De Geest S, Sabaté E. Adherence to long-term therapies: evidence for action. Eur J Cardiovasc Nurs. 2003;323. doi:10.1016/S1474-5151(03) 00091-4

27. Burnier M. Medication adherence and persistence as the cornerstone of effective antihypertensive therapy. Am J Hypertens. 2006;19 (11):1190-1196. doi:10.1016/j.amjhyper.2006.04.006

28. Zhang JX, Yin W, Sun SX, et al. The impact of the Medicare Part D prescription benefit on generic drug use. J Gen Intern Med. 2008;23 (10):1673-1678. doi:10.1007/s11606-008-0742-6

29. Davidoff AJ, Stuart BT, Shoemaker JS, et al. Lessons learned: who didn't enroll in Medicare drug coverage in 2006, and why? Health Aff. 2010;29(6):1255-1263. doi:10.1377/hlthaff.2009.0002

30. Duru OK, Edgington S, Mangione C, et al. Association of Medicare Part D low-income cost subsidy program enrollment with increased fill adherence to clopidogrel after coronary stent placement Pharmacotherapy. 2014;34(12):1230-1238. doi:10.1002/phar.1502
31. Wei LL, Lloyd JT, Shrank WH. The relationship between the low-income subsidy and cost-related nonadherence to drug therapies in Medicare Part D. J Am Geriatr Soc. 2013;61(8):1315-1323. doi:10.1111/jgs.12364

32. Yala SM, Duru O, Ettner SL, et al. Patterns of prescription drug expenditures and medication adherence among Medicare Part D beneficiaries with and without the low-income supplement. $B M C$ Health Serv Res. 2014;14:665. doi:10.1186/s12913-014-0665-3

33. Kun YU, Cao J, Hua FU. Analysis of factors affecting physicians' prescribing conduct. Chin J Hosp Admin. 2002;18:92-94.

34. Chu HL, Liu SZ, Romeis JC. Assessing the effects of drug price reduction policies on older people in Taiwan. Health Serv Manage Res. 2011;24(1):1-7. doi:10.1258/hsmr.2010.010016

35. Tran BX, Hwang J, Nguyen LH, et al. Cost-Related medication nonadherence and cost-saving behaviors among patients with glaucoma before and after the implementation of Medicare part D. JAMA Ophthalmol. 2015;133(9):985-996. doi:10.1001/jamaophthalmol.2015.1671

36. O'Donnell O, Doorslaer EV, Wagstaff A, et al. Analyzing Health Equity Using Household Survey Data: A Guide to Techniques and Their Implementation. The World Bank;2008:147-156. Available from: http://web.worldbank.org/archive/website01411/WEB/ IMAGES/HEALTHEQ.PDF. Accessed July 3, 2019.

37. Basu S, Hong A, Siddiqi A. Using decomposition analysis to identify modifiable racial disparities in the distribution of blood pressure in the United States. Am J Epidemiol. 2015;182(4):345-353. doi:10.1093/aje/kwv079

38. Mortensen K, Song PH. Minding the gap: a secomposition of emergency department use by Medicaid enrollees and the uninsured. Med Care. 2008;46(10):1099-1107. doi:10.1097/ MLR.0b013e318185c92d

39. Saito E, Gilmour S, Yoneoka D, et al. Inequality and inequity in healthcare utilization in urban Nepal: a cross-sectional observational study. Health Policy Plan. 2016;31(7):817-824. doi:10.1093/heapol/czv137

40. Brekke L, Buysman E, Grabner M, et al. The use of decomposition methods in real-world treatment benefits evaluation for patients with type 2 diabetes initiating different injectable therapies: findings from the INITIATOR study. Value Health. 2017;20(10):1252-1259. doi:10.1016/j.jval.2017.05.019

41. Jiang Y, Ni W. Estimating the impact of adherence to and persistence with atypical antipsychotic therapy on health care costs and risk of hospitalization. Pharmacotherapy. 2015;35(9):813-822. doi:10.1002/phar.1634

42. Qin J, Wang J, Zhu D Analysis report of health services survey of Xinjiang production and construction corps, 2010. Xinjiang Production and Construction Corps Press; 2013:68-69.

43. The Cebsus Office of the State Council. Tabulation on the 2010 Population Census of the People's Republic of China. Beijing: China Statistics Press; 2012:51-55. 


\section{Supplemenatary materials}

Table SI Logistic regression analysis between drug benefit program enrollees and non-enrollees

\begin{tabular}{|c|c|c|c|c|}
\hline & \multicolumn{2}{|l|}{ Enrollees } & \multicolumn{2}{|c|}{ Non-enrollees } \\
\hline & OR value & $95 \% \mathrm{Cl}$ & OR value & $95 \% \mathrm{Cl}$ \\
\hline \multicolumn{5}{|l|}{ Predisposing factors } \\
\hline \multicolumn{5}{|l|}{ Gender (reference: male) } \\
\hline Female & 0.937 & $0.523, I .678$ & 0.917 & $0.665,1.266$ \\
\hline Age & 0.978 & $0.940,1.018$ & 0.999 & $0.981,1.019$ \\
\hline \multicolumn{5}{|l|}{ Education (reference: illiterate) } \\
\hline Primary school & 1.110 & $0.566,2.178$ & 1.088 & $0.759,1.560$ \\
\hline Middle school or above & 0.972 & $0.456,2.071$ & 1.272 & $0.846,1.914$ \\
\hline \multicolumn{5}{|l|}{ Enabling factors } \\
\hline \multicolumn{5}{|c|}{ Annual household income (reference: $<48,000$ ) } \\
\hline $48,000-68,400$ & 0.782 & $0.383,1.595$ & 0.697 & $0.482,1.006$ \\
\hline$\geq 68,400$ & 0.887 & $0.442, I .78 I$ & 1.078 & $0.75 \mathrm{I}, \mathrm{I} .547$ \\
\hline \multicolumn{5}{|l|}{ Urbanity (reference: rural) } \\
\hline Urban & 0.981 & $0.507,1.896$ & 0.786 & $0.552,1.118$ \\
\hline \multicolumn{5}{|c|}{ Frequency of clinic check-ups (reference: 0 ) } \\
\hline $\mathrm{I}-2$ & 0.497 & $0.233,1.060$ & 1.013 & $0.690,1.487$ \\
\hline$\geq 3$ & 0.285 & $0.141,0.576$ & 0.608 & $0.421,0.877$ \\
\hline \multicolumn{5}{|l|}{ Need } \\
\hline Diabetic status (reference: no) & 0.783 & $0.430, I .425$ & 0.585 & $0.4 I I, 0.832$ \\
\hline \multicolumn{5}{|l|}{ Yes } \\
\hline \multicolumn{5}{|c|}{ Duration of hypertension (reference: $I-5$ ) } \\
\hline $5-10$ & 0.965 & $0.332,2.803$ & 0.610 & $0.409,0.911$ \\
\hline$\geq 10$ & 0.714 & $0.270, I .885$ & 0.454 & $0.315,0.655$ \\
\hline \multicolumn{5}{|l|}{$\begin{array}{l}\text { Blood pressure control } \\
\text { (reference: uncontrolled) }\end{array}$} \\
\hline Controlled & 0.317 & $0.167,0.600$ & 0.714 & $0.524,0.972$ \\
\hline
\end{tabular}


Table S2 Contribution of drug benefit program effect to the differences in medication nonadherence between drug benefit program enrollees and non-enrollees

\begin{tabular}{|c|c|c|c|c|}
\hline & Coefficient & $P$ & $95 \% \mathrm{Cl}$ & $\%$ of contribution \\
\hline \multicolumn{5}{|l|}{ Predisposing factors } \\
\hline \multicolumn{5}{|l|}{ Gender (reference: male) } \\
\hline Female & -0.001 & 0.952 & $-0.030,0.028$ & $-1.51 \%$ \\
\hline Age & 0.128 & 0.334 & $-0.131,0.387$ & $213.92 \%$ \\
\hline \multicolumn{5}{|c|}{ Education (reference: illiterate) } \\
\hline Primary school & -0.001 & 0.960 & $-0.022,0.021$ & $-0.94 \%$ \\
\hline Middle school or above & 0.007 & 0.545 & $-0.015,0.030$ & $11.89 \%$ \\
\hline \multicolumn{5}{|l|}{ Enabling factors } \\
\hline \multicolumn{5}{|c|}{ Annual household income (reference: $<48,000$ ) } \\
\hline $48,000-68,400$ & -0.003 & 0.779 & $-0.026,0.019$ & $-5.35 \%$ \\
\hline$\geq 68,400$ & 0.007 & 0.629 & $-0.021,0.035$ & $11.49 \%$ \\
\hline \multicolumn{5}{|l|}{ Urbanity (reference: rural) } \\
\hline Urban & -0.006 & 0.566 & $-0.024,0.013$ & $-9.23 \%$ \\
\hline \multicolumn{5}{|c|}{ Frequency of clinic check-ups (reference: 0 ) } \\
\hline $\mathrm{I}-2$ & 0.016 & 0.104 & $-0.003,0.034$ & $25.98 \%$ \\
\hline$\geq 3$ & 0.036 & 0.038 & $0.002,0.070$ & $60.55 \%$ \\
\hline \multicolumn{5}{|l|}{ Need } \\
\hline \multicolumn{5}{|l|}{ Diabetic status (reference: no) } \\
\hline Yes & -0.008 & 0.432 & $0.029,0.012$ & $-13.98 \%$ \\
\hline \multicolumn{5}{|c|}{ Duration of hypertension (reference: $1-5$ ) } \\
\hline $5-10$ & -0.007 & 0.436 & $-0.025,0.011$ & $-11.76 \%$ \\
\hline$\geq 10$ & -0.026 & 0.406 & $-0.090,0.037$ & $-45.01 \%$ \\
\hline \multicolumn{5}{|c|}{ Blood pressure control (reference: uncontrolled) } \\
\hline Controlled & 0.028 & 0.005 & $0.008,0.048$ & $46.93 \%$ \\
\hline
\end{tabular}


Table S3 Contribution of observed characteristics to the differences in medication nonadherence between drug benefit program enrollees and non-enrollees

\begin{tabular}{|c|c|c|c|c|}
\hline & Coefficient & $\boldsymbol{P}$ & $95 \% \mathrm{Cl}$ & $\%$ of contribution \\
\hline \multicolumn{5}{|l|}{ Predisposing factors } \\
\hline \multicolumn{5}{|l|}{ Gender (reference: male) } \\
\hline Female & -0.001 & 0.603 & $-0.005,0.003$ & $-1.61 \%$ \\
\hline Age & 0.000 & 0.992 & $-0.002,0.002$ & $0.17 \%$ \\
\hline \multicolumn{5}{|c|}{ Education (reference: illiterate) } \\
\hline Primary school & -0.000 & 0.647 & $-0.002,0.001$ & $-0.68 \%$ \\
\hline Middle school or above & -0.002 & 0.252 & $-0.005,0.001$ & $-2.95 \%$ \\
\hline \multicolumn{5}{|l|}{ Enabling factors } \\
\hline \multicolumn{5}{|l|}{$\begin{array}{l}\text { Annual household income } \\
\text { (reference: }<48,000 \text { ) }\end{array}$} \\
\hline $48,000-68,400$ & -0.000 & 0.057 & $-0.001,0.000$ & $-0.60 \%$ \\
\hline$\geq 68,400$ & -0.001 & 0.684 & $-0.008,0.005$ & $-2.35 \%$ \\
\hline \multicolumn{5}{|l|}{ Urbanity (reference: rural) } \\
\hline Urban & 0.000 & 0.184 & $-0.000,0.000$ & $0.23 \%$ \\
\hline \multicolumn{5}{|c|}{ Frequency of clinic check-ups (reference: 0 ) } \\
\hline $1-2$ & 0.000 & 0.948 & $-0.00 I, 0.001$ & $0.06 \%$ \\
\hline$\geq 3$ & 0.007 & 0.009 & $0.002,0.012$ & $11.86 \%$ \\
\hline \multicolumn{5}{|l|}{ Need } \\
\hline \multicolumn{5}{|c|}{ Diabetic status (reference: no) } \\
\hline Yes & 0.004 & 0.001 & $0.002,0.007$ & $7.18 \%$ \\
\hline \multicolumn{5}{|c|}{ Duration of hypertension (reference: $1-5$ ) } \\
\hline $5-10$ & -0.004 & 0.022 & $-0.008,-0.001$ & $-7.22 \%$ \\
\hline$\geq 10$ & 0.019 & $<0.001$ & $0.010,0.029$ & $32.13 \%$ \\
\hline \multicolumn{5}{|c|}{ Blood pressure control (reference: uncontrolled) } \\
\hline Controlled & 0.002 & 0.034 & $0.000,0.003$ & $3.02 \%$ \\
\hline
\end{tabular}




\section{Publish your work in this journal}

Patient Preference and Adherence is an international, peer-reviewed, open access journal that focusing on the growing importance of patient preference and adherence throughout the therapeutic continuum. Patient satisfaction, acceptability, quality of life, compliance, persistence and their role in developing new therapeutic modalities and compounds to optimize clinical outcomes for existing disease states are major areas of interest for the journal. This journal has been accepted for indexing on PubMed Central. The manuscript management system is completely online and includes a very quick and fair peer-review system, which is all easy to use. Visit http:// www.dovepress.com/testimonials.php to read real quotes from published authors. 